\title{
Efektivitas Pemanfaatan Serbuk Gergaji dan Limbah Media Tanam Jamur (Baglog) sebagai Bahan Baku Pembuatan Biogas
}

\author{
Dikdik Mulyadi, Lela Mukmilah Y., Desi Kusumawati
}

Program studi Kimia Universitas Muhammadiyah Sukabumi

Email:dikdik2008@yahoo.co.id

Received: April 2016; Revised: Mei 2016; Accepted: Mei 2016; Available Online: Mei 2016

\begin{abstract}
Abstrak
Biogas merupakan salah salah satu jenis energi yang dapat dihasilkan melalui fermentasi anerobik terhadap senyawa organik. Penelitian ini bertujuan mengetahui efektivitas pemanfaatan limbah media tanam jamur (baglog) dengan serbuk gergaji sebagai bahan baku pembuatan biogas menggunakan aktivator kotoran sapi. Penelitian dilakukan melalui fermentasi secara anaerobik terhadap sampel yang mengandung limbah baglog (sampel 1) dan serbuk gergaji (sampel 2), dengan penambahan aktivator kotoran sapi kepada masing-masing sampel. Kedua sampel tersebut dilakukan fermentasi secara anaerobik selama 32 hari, kemudian dilakukan pengukuran volume biogas setiap 4 hari sekali selama 32 hari. Kadar gas metana sampel 1 dan sampel 2 diukur menggunakan kromatografi gas. Untuk melihat pengaruh penambahan aktivator kotoran sapi terhadap masingmasing sampel maka dilakukan pengukuran volume biogas terhadap kotoran sapi (kontrol) tanpa penambahan limbah baglog dan serbuk gergaji. Proses pendegradasian baglog dan serbuk gergaji dengan aktivator kotoran sapi dapat dilihat melalui beberapa parameter yaitu dengan menguji total solid (TS), total volatile solid (TVS), volatile fatty acids (VFA), derajat keasaman $(\mathrm{pH})$, dan rasio $\mathrm{C} / \mathrm{N}$. Hasil penelitian menunjukkan. Efektivitas sampel 1 menghasilkan jumlah volume biogas rata-rata $28 \%$ lebih tinggi dibandingkan sampel 2. Kandungan gas metana pada limbah baglog dan serbuk gergaji dengan aktivator kotoran sapi masing-masing sebesar 54\% dan $0.21 \%$. Proses fermentasi pembuatan biogas pada penelitian ini sampai hari ke-32 berlangsung pada $\mathrm{pH} 7$, dengan nilai TS,TVS dan VFA mengalami kecenderungan menurun setelah proses fermentasi sedangkan rasio $\mathrm{C} / \mathrm{N}$ limbah baglog lebih rendah dibanding serbuk gergaji .
\end{abstract}

Kata kunci: Serbuk gergaji, limbah baglog, biogas, fermentasi, gas metana

\begin{abstract}
Biogas is one of energy that can be produced by anaerobic fermentation of the organic compounds. The objective of this study was to determine the effectiveness of the utilization of waste of media mushroom growth (baglog) with sawdust as raw material for biogas with cow dung activators. The study was conducted through anaerobic fermentation of the samples containing waste baglog (sample 1) and sawdust (sample 2), with the addition of cow manure activator to each sample. Both of these samples do anaerobic fermentation for 32 days, then measuring the volume of biogas every 4 days for 32 days. Methane content in samples 1 and 2 measured by using gas chromatography. To see the effect of the addition of activators cow dung biogas volume measurement was carried out with cow dung without addition baglog waste and sawdust. The process of degradation baglog and sawdust with an activator of cow dung could be observed in some of the parameters through total solids (TS), total volatile solids (TVS), volatile fatty acids (VFA), the degree of acidity (pH), and $\mathrm{C} / \mathrm{N}$ ratio. The results showed that effectiveness of sample 1 resulted in the everage of total volume biogas $28 \%$ higher than sample 2. The content of methane in sample 1 and sampel 2 was $54 \% \%$, and $0.21 \%$ respectively. The fermentation process biogas production in this experiment was carried out at $\mathrm{pH} 7$, with a value of TS, TVS and VFA showed a decrease trend after the fermentation process, $\mathrm{C} / \mathrm{N}$ ratiowas lower than the baglog waste sawdust until day 32 retention time.
\end{abstract}

Keywords: Sawdust, baglog waste, biogas, fermentation, methane

DOI : http://dx.doi.org/10.15408/jkv.v2i1.3100 


\section{PENDAHULUAN}

Peningkatan jumlah penduduk mengakibatkan tingkat konsumsi energi semakin meningkat, sedangkan sumber energi fosil sangat terbatas, sehingga diperlukan upaya untuk mendapatkan energi terbarukan. Indonesia memiliki potensi kekayaan alam yang sangat melimpah untuk menghasilkan sumber energi alternatif. Salah satunya adalah pemanfaatannya limbah peternakan untuk pembuatan biogas. Di Indonesia pembuatan dan penggunaan biogas telah digalakkan pada awal 1970-an, terutama untuk memanfaatkan sisa buangan dari bahan yang tidak bermanfaat menjadi media yang bermanfaat (Harahap, 2007).

Biogas adalah gas yang dihasilkan secara mikrobiologi anaerobik dari limbah organik (Khorsidi dan Arikan, 2008). Saat ini pemanfaatan bahan organik sebagai bahan baku pembuatan biogas masih sedikit. Disisi lain limbah media tanam jamur (baglog) yang dihasilkan dari proses budidaya jamur dengan baku serbuk gergaji semakin mengalami peningkatan baik mutu maupun jumlahnya. Peningkatan jumlah budidaya jamur dari bahan baku serbuk gergaji akan berdampak pada peningkatan limbah baglog yang dihasilkan (Kusuma, 2014). Di Indonesia jamur tiram merupakan komoditi yang mempunyai prospek sangat baik untuk dikembangkan, baik untuk mencukupi pasaran dalam negeri yang terus meningkat maupun untuk ekspor, sebab masyarakat sudah mulai memahami nilai gizi jamur tiram putih ataupun coklat. Akhir-akhir ini produksi jamur tiram semakin meningkat namun pengolahan limbah baglog masih belum maksimal. Pemanfatan limbah baglog umumnya hanya digunakan sebagai pupuk tanaman, kompos dan briket bahkan banyak yang hanya dibuang begitu saja (Kusuma, 2014).

$$
\text { Penelitian biogas dengan }
$$

memanfaatkan limbah baglog belum dilakukan, padahal limbah baglog berpotensi untuk dijadikan sebagai bahan baku biogas karena masih mengandung bahan organik. sehingga untuk memaksimalkan potensi limbah baglog yang lebih ekonomis, maka perlu dilakukan penelitian efektivitas pemanfaatan limbah baglog sebagai bahan baku pembuatan biogas dibandingkan dengan penelitian terhadap serbuk gergaji yang telah banyak dilakukan untuk pembuatan biogas dengan aktivator kotoran sapi (Harahap, 2007).
Rumusan permasalahan yang akan dilakukan dalam penelitian ini adalah seberapa besar volume biogas dihasilkan dari limbah baglog dan serbuk gergaji yang diberi aktivator kotoran sapi. Untuk melihat pengaruh penambahan aktivator kotoran sapi maka dilakukan pengukuran volume biogas terhadap kotoran sapi tanpa penambahan limbah baglog dan serbuk gergaji.

\section{METODE PENELITIAN}

\section{Bahan dan Alat}

Bahan baku substrat adalah limbah baglog, serbuk gergaji kotoran sapi dan air. Bahan kimia yang digunakan meliputi aquades, $\mathrm{HCl} 0.5 \mathrm{~N}, \mathrm{H}_{2} \mathrm{SO}_{4}$ pekat, $\mathrm{H}_{2} \mathrm{SO}_{4}$ $15 \%, \quad \mathrm{NaOH} \quad 0.5 \mathrm{~N}, \quad$ dan Indikator Phenolphtalein.

Alat yang digunakan dalam proses pembuatan biogas ini adalah diligen $20 \mathrm{~L}$, pipa selang, plastik penampung gas, alat pengukur gas. Sedangkan dalam pengukuran analisa terhadap proses pembentukan biogas diperlukan peralatan laboratorium, dan kromatografi gas.

\section{Persiapan Alat}

Persiapan biodigester anaerobik menggunakan reaktor batch dengan kapasitas 20 L. Biodigester ditutup rapat dan dihubungkan dengan selang kemudian selang tersebut dihubungkan dengan plastik penampung gas.Pada saat fermentasi selang 2 ditutup dengan penjepit.

Pengukuran volume gas yang dihasilkan dilakukan dengan menambahkan air pada alat pengukur gas hingga menunjukan skala $0 \mathrm{ml}$, tutup terlebih dahulu selang 1 dengan penjepit kemudian menghubungkan selang 2 pada penampung gas dengan alat pengukur gas dan melihat penurunan volume air pada skala yang tertera pada alat pengukur gas. Reaktor alat pengukur biogas yang dihasilkan dapat dilihat pada gambar 1 .

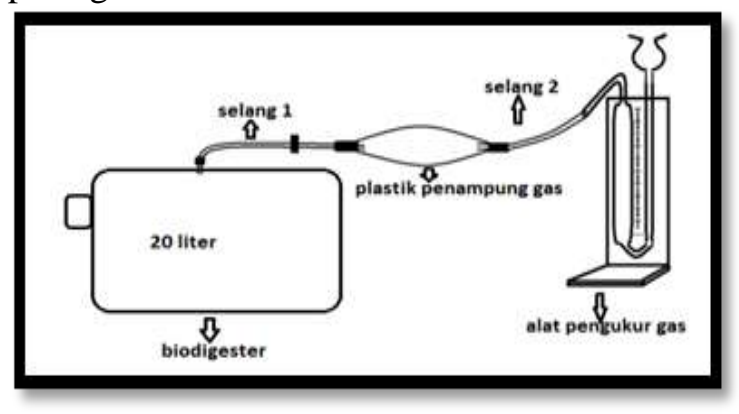

Gambar 1. Reaktor biogas dan pengukur volume gas 


\section{Proses Pencampuran}

Biodigester diisi dengan volume total campuran sampel sebanyak 12 L Perbandingan bahan baku dengan air adalah 1:1 dan perbandingan setiap sampel dengan aktivator adalah 1:1. Sampel dicampur sesuai variasi sampel yang telah ditentukan kemudian diaduk merata kemudian diukur $\mathrm{pH}$ masing- masing sampel dengan menggunakan indikator universal setelah itu setiap sampel dimasukkan ke dalam biodigester dan ditutup rapat kemudian didiamkan. Volume biogas yang dihasilkan pada penampung biogas diukur setiap 4 hari sekali dengan alat pengukur biogas, fermentasi dihentikan setelah hari ke 32. Komposisi isian biogas dapat dilihat pada tabel 1 .

Tabel 1. Komposisi bahan baku pembuatan biogas

\begin{tabular}{|c|c|c|c|}
\hline $\begin{array}{c}\text { Kode } \\
\text { Sampel }\end{array}$ & $\begin{array}{c}\text { Bahan } \\
\text { Baku (3 Kg) }\end{array}$ & $\begin{array}{c}\text { Aktivator } \\
(3 \mathrm{Kg})\end{array}$ & $\begin{array}{c}\text { Air } \\
\text { (Liter) }\end{array}$ \\
\hline $\begin{array}{l}\text { Sampel } \\
1\end{array}$ & $\begin{array}{l}\text { Limbah } \\
\text { Baglog }\end{array}$ & $\begin{array}{c}\text { Kotoran } \\
\text { sapi }\end{array}$ & 6 \\
\hline $\begin{array}{l}\text { Sampel } \\
2\end{array}$ & $\begin{array}{l}\text { Serbuk } \\
\text { Gergaji }\end{array}$ & $\begin{array}{c}\text { Kotoran } \\
\text { sapi }\end{array}$ & 6 \\
\hline Kontrol & - & $\begin{array}{c}\text { Kotoran } \\
\text { sapi }\end{array}$ & 6 \\
\hline
\end{tabular}

\section{Pengukuran volume biogas}

Volume biogas sampel 1, sampel 2 dan kontrol diukur setiap 4 hari sekali selama 32 hari. Jumlah volume rata-rata tertinggi sampel 1 dan 2 diukur kadar gas metannyaa pada hari ke-32 menggunakan gas kromatografi.

\section{Uji Total Solid (TS)}

Memasukkan cawan timbang ke dalam oven pada suhu $105{ }^{\circ} \mathrm{C}$ selama 30 menit. Mendinginkan cawan timbang yang sudah dipanaskan pada desikator selama 15 menit sampai suhu cawan timbang sama dengan suhu kamar, lalu menimbang dan mencatat bobot kosong cawan. Menimbang \pm 3 gram sampel pada cawan timbang dan mencatat ( bobot cawan + bobot contoh ), kemudian dimasukkan ke dalam oven $105{ }^{0} \mathrm{C}$ selama 4 jam. Mendinginkan cawan timbang berisi residu pada desikator selam 15 menit, kemudian menimbang cawan timbang uang berisi residuresidu .

\section{Uji Total Volatile Solid (TVS)}

Setelah sampel dikeringkan pada suhu

$103{ }^{\circ} \mathrm{C}$, kemudian dilanjutkan dengan pemanasan pada suhu $550{ }^{\circ} \mathrm{C}$ selama 30 menit, kemudian didinginkan dalam desikator, dan menimbang cawan.

\section{Uji Volatile Fatty Acid(VFA)}

Total Konsentrasi VFA diukur menggunakan teknik destilasi uap. $5 \mathrm{~mL}$ supernatan dimasukkan ke dalam tabung destilasi, kemudian ditambahkan $1 \mathrm{ml} \mathrm{H}_{2} \mathrm{SO}_{4}$ $15 \%$. Dinding tabung dibilas dengan aquadest dan secepatnya ditutup dengan sumbat karet yang telah dihubungkan dengan pipa destilasi berdiameter $\pm 0.5 \mathrm{~cm}$. Kemudian ujung pipayang lain dihubungkan dengan alat pendingin Laibig. Tabung destilasi dimasukkan ke dalam labu didih yang telah berisi air men didih tanpa menyentuh permukaan air tersebut. Hasil destilasi ditampung dengan labu erlenmeyer $500 \mathrm{ml}$ yang telah diisi $5 \mathrm{ml} \mathrm{NaOH} 0.5 \mathrm{~N}$. Proses destilasi selesai pada saat jumlah destilat yang ditampung mencapai $300 \mathrm{ml}$. Destilat yang tertampung ditambah indikator phenophtalein (PP) sebanyak 2- 3 tetes, lalu dititrasi dengan $\mathrm{HCl} 0.5 \mathrm{~N}$ sampai terjadi perubahan warna.

\section{Rasio C/N}

Pengukuran rasio $\mathrm{C} / \mathrm{N}$ dilakukan dengan menghitung perbandingan nilai Total C-organik dan Nitrogen Total yang diperoleh dari data hasil analisis

\section{HASIL DAN PEMBAHASAN}

\section{Volume biogas yang dihasilkan}

Gambar 2 menjelaskan volume biogas yang dihasilkan dari campuran limbah baglog (sampel 1) dan serbuk gergaji (sampel 2) yang masing-masing telah diberi aktivator kotoran sapi serta kontrol yang mengandung hanya kotoran sapi diukur setiap 4 hari sekali sampai hari ke-32. Berdasarkan Gambar 2, sampai hari ke-32 bahwa jumlah volume rata-rata biogas yang dihasilkan oleh sampel 1, 28\% lebih tinggi dibandingan dengan volume biogas yang dihasilkan oleh sampel 2 . Pada gambar 2 juga terlihat adanya pengaruh penambahan aktivator kotoran sapi pada limbah baglog dan serbuk gergaji, dimana volume rata-rata biogas yang dihasilkan pada kontrol lebih sedikit dibandingkan sampel 1 dan 2. Volume biogas tertinggi yang dihasilkan antara sampel 1 dan 2 diperoleh pada proses fermentasi hari ke-24. Hal ini menunjukkan bahwa bakteri metanogenik bekerja optimum 
pada hari ke-24. Setelah hari ke-24 volume biogas cenderung mengalami penurunan.

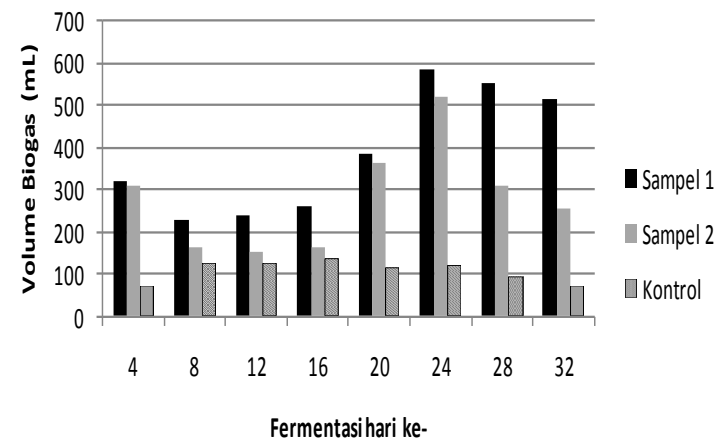

Gambar 2. Volume biogas yang dihasilkan per 4 hari

Terbentuknya biogas pada penelitian ini dapat disebabkan oleh adanya perubahan total solid (TS) sebelum dan sesudah proses fermentasi, yang menunjukan adanya proses pedegradasian padatan organik menjadi senyawa yang lebih sederhana. Nilai TS pada awal fermentasi dan akhir fermentasi dapat dilihat pada Gambar 3.

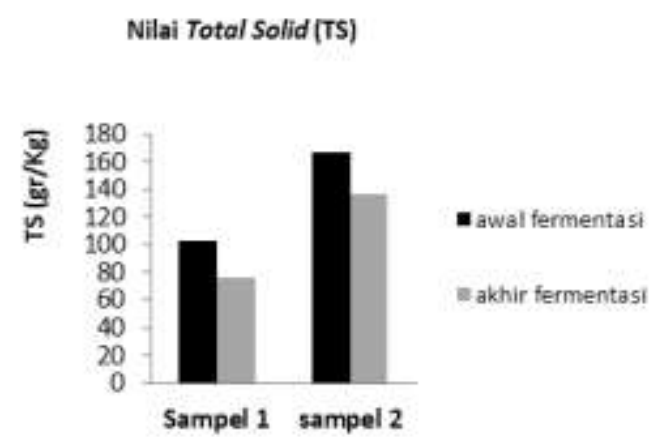

Gambar 3. Nilai total solid

Nilai TS pada serbuk gergaji lebih tinggi baik sebelum maupun sesudah proses fermentasi. Hal ini dapat disebabkan limbah baglog telah mengalami pendegradasian selama digunakan sebagi media tanam jamur. Nilai TS pada limbah baglog dan serbuk gergaji cenderung mengalami penurunan dari awal hingga akhir fermentasi, walaupun penurunannya kurang dari $50 \%$ sampai akhir proses fermentasi.

Perubahan Nilai Total volatile solid (TVS) pada awal fermentasi dan akhir fermentasi juga mempengaruhi proses terbentuknya biogas seperti terlihat pada Gambar 4. Perubahan nilai TVS cenderung mengalami penurunan dari awal sampai akhir fermentasi menurut (Boulaghui et al., 2003) pada proses produksi biogas secara anaerobik, terjadi penurunan kadar TVS walaupun efesiensi pendegradasian baik limbah baglog maupun serbuk gergaji setelah proses fermentasi kurang dari 50\% sampai akhir proses.

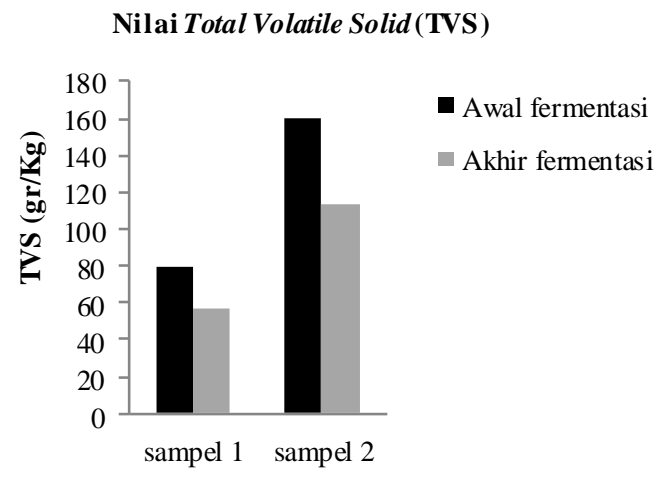

Gambar 4. Nilai total volatile solid

Penurunan nilai TVS menunjukan bahwa kandungan padatan organik telah didegradasi menjadi senyawa volatile fatty acids (VFS), alkohol, $\mathrm{CO}_{2}$, dan $\mathrm{H}_{2}$ pada tahap asidogenesis. Nilai TVS pada setiap sampel cenderung mengalami penurunan pada setiap sampel, keadaan ini disebabkan bahan organik yang ada sudah mengalami reaksi hidrolisis hingga reaksi metanogenesis (Herawati dan wibawa, 2010) sesuai Gambar 4 penurunan TVS yang lebih tinggi terjadi pada serbuk gergaji. Selain itu nilai volatile fatty acid (VFA) juga berpengaruh terhadap pembentukan biogas dimana, VFA merupakan produk dari asidogenesis sebelum dirombak lebih lanjut menjadi gas metana, nilai VFA awal fermentasi dan akhir fermentasi dapat dilihat pada Gambar 5.

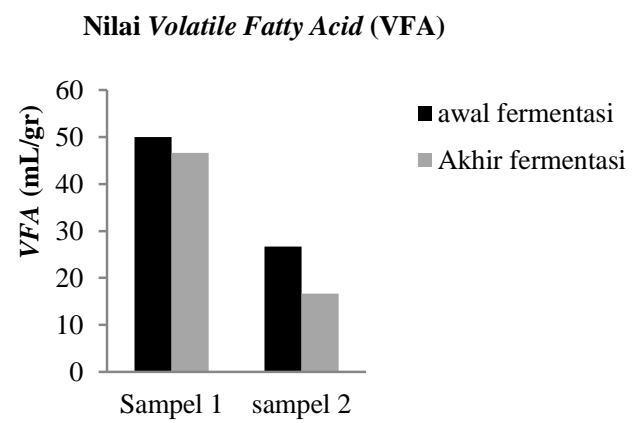

Gambar 5. Nilai volatile fatty acid 
Nilai VFA pada awal hingga akhir cenderung mengalami penurunan hal ini membuktikan bahwa terjadi perubahan pada produk asidogenesis menjadi gas metana. Kondisi lain yang mempengaruhi terbentuknya biogas adalah kondisi pH. Berdasarkan Tabel 2 terlihat bahwa kondisi $\mathrm{pH}$ pembuatan biogas pada penelitian ini sesuai dengan kondisi pertumbuhan bakteri metanogenik yakni 7,28,2 (Yuwono dan Suhartanto, 2013 )

Tabel 2. Nilai $\mathrm{pH}$ awal dan akhir proses fermentasi

\begin{tabular}{lcc}
\hline Kode sampel & \multicolumn{2}{c}{$\mathrm{pH}$} \\
\cline { 2 - 3 } & Awal & Akhir \\
\hline Sampel 1 & 7 & 7 \\
Sampel 2 & 7 & 7 \\
Kontrol & 7 & 7 \\
\hline
\end{tabular}

Volume biogas yang dihasilkan pada sampel 1 yang mengandung limbah baglog lebih tinggi dibandingkan dengan sampel 2 yang mengandung serbuk gergaji, hal ini dapat disebabkan pengaruh rasio $\mathrm{C} / \mathrm{N}$ bahan bakunya. Berdasarkan Tabel 3 bahwa bahan baku limbah baglog memiliki rasio $\mathrm{C} / \mathrm{N}$ lebih rendah dibandingkan dengan serbuk gergaji, sehingga pembentukan biogas oleh bakteri metanogenik pada limbah baglog lebih mudah dibandingkan dengan serbuk gergaji. Hal ini sesuai dengan penelitian yang dilakukan oleh Yong et al., 2013 bahwa bahan baku yang memiliki Rasio $\mathrm{C} / \mathrm{N}$ lebih tinggi akan sulit untuk diuraikan oleh bakteri.

Tabel 3. Rasio $\mathrm{C} / \mathrm{N}$ bahan baku biogas

\begin{tabular}{llll}
\hline Parameter & $\begin{array}{l}\text { Limbah } \\
\text { Baglog }\end{array}$ & $\begin{array}{l}\text { Serbuk } \\
\text { gergaji }\end{array}$ & $\begin{array}{l}\text { Kotoran } \\
\text { sapi }\end{array}$ \\
\hline Karbon (C) & 16.76 & 31.79 & 10.56 \\
Nitrogen (N) & 0.29 & 0.36 & 0.17 \\
Rasio C/N & 57.79 & 88.30 & 62.12 \\
\hline
\end{tabular}

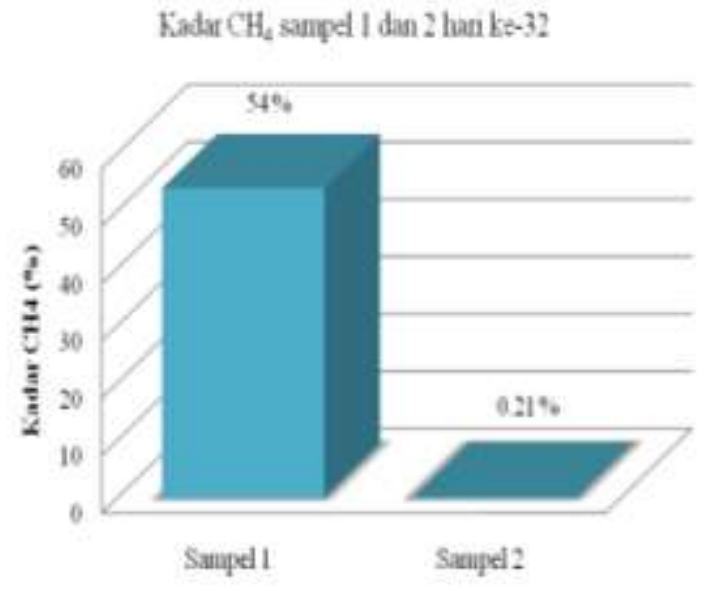

Gambar 6. Kadar gas $\mathrm{CH}_{4}$ sampel 1 dan 2 hari ke32

Untuk melihat kadar gas metana pada sampel 1 dan 2 pada hari ke-32 dilakukan pengkuran dengan menggunakan kromatografi gas. Berdasarkan Gambar 6, sampel 1 mengandung gas metana sebagai penyusun utama biogas sebesar 54\%, sedangkan sampel 6 hanya $0.21 \%$. Persentasi gas metana yang mencapai $54 \%$ pada sampel 2, sesuai dengan penelitian yang dilakukan oleh Fantozi dan Buratti., 2011. bahwa kadar gas metana dalam biogas berkisar antara 40-62\%. Dengan demikian limbah baglog lebih efektif sebagai bahan baku pembuatan biogas dibandingkan dengan serbuk gergaji.

\section{SIMPULAN}

Hasil penelitian menunjukkan. efektivitas sampel 1 menghasilkan jumlah volume biogas rata-rata $28 \%$ lebih tinggi dibandingkan sampel 2. Kandungan gas metana pada limbah baglog dan serbuk gergaji dengan aktivator kotoran sapi masing-masing sebesar $54 \%$ dan $0.21 \%$. Proses fermentasi pembuatan biogas pada penelitian ini berlangsung pada $\mathrm{pH} \mathrm{7,} \mathrm{dengan} \mathrm{nilai} \mathrm{TS,TVS}$ dan VFA mengalami kecenderungan menurun setelah proses fermentasi sedangkanm rasio $\mathrm{C} / \mathrm{N}$ limbah baglog lebih rendah dibanding serbuk gergaji sampai hari ke-32. 


\section{UCAPAN TERIMA KASIH}

Kami sampaikan ucapan terima kasih yang sebesar-besarnya, kepada LPPM Universitas Muhammadiyah Sukabumi yang telah memberikan bantuan dana untuk kegiatan penelitian ini.

\section{DAFTAR PUSTAKA}

Bouallagui H, R Ben Cheikh, L Marouani, M Hamdi. 2003. Mesophilic biogas production from fruit and vegetable waste in a tubular digester. J.Biores. Technol. 86:85-89.

Fantozi F, Buratti C. 2011. Anaerobic digestion of mechanically treated Of MSW: experimental data on biogas/methane production and residues characterization. Bioresource Technology. 102: 8885-8892.

Harahap. 2007. Uji Beda Komposisi Campuran Kototran Sapi dengan Beberapa Jenis Limbah Pertanian Terhadap Biogas yang Dihasilkan. Skripsi, Departemen Teknologi Pertanian Fakultas Pertanian, Universitas Sumatra Utara.
Herawati DA, Wibawa AA. 2010. Pengaruh preatreatment jerami padi pada produksi biogas dari jerami padi dan sampah sayurr sawi hijau secara batch. Jurnal rekayasa proses: $4(1)$.

Khorshidi N, Arikan B. 2008. Experimental Practice in order to Increasing Efficiency of Biogas Production by Treating Digestate of Sludge. Tesis, University College of Boras School of Engineering.

Kusuma W. 2014. Kandungan Nitrogen (N), Fospor (P), Kalium (K) Limbah Jamur Tiram (Rleurotusostreatus) dan Jamur Kuping (Auricularia auricular) Guna Pemanfaatannya sebagai Pupuk. Skripsi, Fakultas Peternakan, Universitas Hasanuddin.

Yong Z, Dong Y, Zhang Xu, Tan T. 2015. Anaerobic co-digestion of food waste and straw for biogas production. Renewable Energy . 78: 527-530.

Yuwono CW, Soehartanto T. 2013. Perancangan sistem pengaduk pada bioreaktor batch untuk meningkatkan produksi biogas. Jurnal Teknik Pomits. 2(1): 2337-3539. 